\title{
A comparison of immunomagnetic separation and direct culture for the isolation of verocytotoxin- producing Escherichia coli 0157 from cases of bloody diarrhoea, non-bloody diarrhoea and asymptomatic contacts
}

\author{
P. A. CHAPMAN and C. A. SIDDONS \\ Public Health Laboratory, Herries Road, Sheffield S5 7BO
}

\begin{abstract}
Enrichment culture in modified buffered peptone water followed by immunomagnetic separation (IMS) with magnetic beads coated with an antibody against Escherichia coli 0157 was compared with direct culture on cefixime rhamnose sorbitol MacConkey agar (CR-SMAC) and cefixime tellurite sorbitol MacConkey agar (CT-SMAC) for the isolation of $E$. coli 0157 from human faeces. In total, 690 samples were examined; $E$. coli 0157 was isolated from 25 samples by IMS but from only 15 and 12 by direct culture on CT-SMAC and CR-SMAC, respectively. The difference in sensitivity of detection was at its most marked on screening repeat faecal samples from known cases and samples from asymptomatic contacts, when of 12 strains of $E$. coli 0157 isolated by IMS, only five were isolated by direct culture. IMS is a sensitive and simple technique for the isolation of $E$. coli 0157 from human faecal samples and should prove useful in elucidating further the epidemiology of this micro-organism.
\end{abstract}

\section{Introduction}

Verocytotoxin-producing Escherichia coli (VTEC) strains are now recognised as a major cause of both haemorrhagic colitis (HC) and the haemolytic uraemic syndrome (HUS), conditions with high morbidity and mortality. In the UK, verocytotoxin-producing $\left(\mathrm{VT}^{+}\right)$ strains of $E$. coli $\mathrm{O} 157$, the most common serogroup associated with illness in man, have been isolated from cattle [1-3], and beef, beef products, milk and milk products have been identified as sources of human infection [2-4]. Person-to-person transmission has also been reported [5-7], but the relative importance of this route of spread is unclear. In view of the potential severity of infections caused by $\mathrm{VT}^{+} E$. coli 0157 strains it is essential that the most sensitive methods available are used in studies designed to elucidate further the epidemiology of the micro- organism.

$\mathrm{VT}^{+}$E. coli $\mathrm{O} 157$ strains do not ferment sorbitol whereas most other serogroups of $E$. coli do, so that sorbitol MacConkey (SMAC) agar has proved useful for their isolation [8]. Improvements to SMAC medium $[9,10]$ have resulted in increased sensitivity

Received 5 Sept. 1995; accepted 6 Oct. 1995. Corresponding author: Dr P. Chapman. of isolation of E. coli 0157 strains from faecal samples but efficient selective enrichment media have not been described. Enrichment culture in buffered peptone water with antibiotics, with subculture to SMAC supplemented with cefixime $0.05 \mathrm{mg} / \mathrm{L}$ and rhamnose $0.5 \% \mathrm{w} / \mathrm{v}$ (CR-SMAC) [9] has been used previously for isolating $E$. coli 0157 strains from beef carcasses [2] but was of low sensitivity, detecting an initial inoculum of only $2000 \mathrm{cfu} / 10 \mathrm{~g}$ of beef. Inclusion of an immunomagnetic separation (IMS) step in the isolation procedure enhanced this sensitivity at least 100 -fold to a detection limit of 2-20 cfu/ $10 \mathrm{~g}$ of beef [11]. When IMS was used to examine bovine faecal suspensions inoculated with 12 different strains of $E$. coli 0157 , it was c. 100 -fold more sensitive in detecting the organism than direct culture [12], an increase in sensitivity that was borne out in a field study of a dairy herd, when of 84 strains of E. coli 0157 isolated from 1024 rectal swabs taken from cattle over a 4-month period, 23 were isolated by both direct culture and IMS, but 61 were isolated by IMS only [12]. The aim of this study was to evaluate the use of enrichment culture in modified buffered peptone water [2] followed by IMS with magnetic beads coated with an antibody to $E$. coli $\mathrm{O} 157$ for the isolation of $E$. coli $\mathrm{O} 157$ from faecal samples from cases of acute bloody and non-bloody diarrhoea and from repeat samples and asymptomatic contacts of these cases. 


\section{Materials and methods}

\section{Selection of faecal samples}

The study was conducted between 1 July 1994 and 30 June 1995. Faecal samples from patients with bloody diarrhoea or non-bloody diarrhoea were selected from those submitted to the laboratory by general practitioners and local hospitals on the basis of information on the request form, or because blood was present in the sample. Wherever possible, samples from asymptomatic contacts and repeat samples from positive patients were collected by Sheffield and Rotherham Environmental Health Departments and submitted to Sheffield Public Health Laboratory. Repeat samples were collected at intervals ranging from 1 week to 3 months after the date of onset of initial symptoms.

\section{Direct culture of E. coli $O 157$}

Approximate $10-\mu \mathrm{l}$ volumes of faecal samples were inoculated directly on to cefixime rhamnose sorbitol MacConkey (CR-SMAC) medium [9] and cefixime tellurite sorbitol MacConkey (CT-SMAC) medium [10]. After overnight incubation at $37^{\circ} \mathrm{C}$, sorbitol and rhamnose non-fermenting colonies from CR-SMAC and sorbitol non-fermenting colonies from CT-SMAC were tested for agglutination with a latex test kit (Oxoid, DR622) for detecting E. coli O157. Isolates that gave positive results with this test were further characterised as described below.

\section{Immunomagnetic separation of E. coli 0157}

After direct culture had been made, c. $0.5 \mathrm{~g}$ of faecal sample was placed in $5 \mathrm{ml}$ of buffered peptone water (Oxoid, CM509) supplemented with vancomycin $8 \mathrm{mg}$ / $\mathrm{L}$, cefixime $0.05 \mathrm{mg} / \mathrm{L}$ and cefsulodin $10 \mathrm{mg} / \mathrm{L}$ (BPWVCC), to inhibit the growth of gram-positive organisms, aeromonads and Proteus spp. [2]. After vortex mixing, broths were incubated at $37^{\circ} \mathrm{C}$ for $6 \mathrm{~h}$ and $1 \mathrm{ml}$ of broth was then added to $20 \mu 1$ of magnetic beads coated with an antibody against $E$. coli 0157 (Dynabeads anti-E. coli O157; Dynal, Oslo) in a 1.5$\mathrm{ml}$ microcentrifuge tube. The beads were suspended evenly in the broth culture by vortex mixing and were placed in a rotating mixer so that they were mixed by inversion every $2-3 \mathrm{~s}$ for $30 \mathrm{~min}$ at ambient temperature. Tubes were placed in a magnetic separator rack (MPC-10, Dynal) and the magnets were placed in position and left for $5 \mathrm{~min}$. The culture supernate was removed by aspiration with a pasteur pipette, the magnetic slide was removed from the rack, the beads were washed by resuspension in $1 \mathrm{ml}$ of PBS, $\mathrm{pH} \mathrm{7.2,}$ with Tween-20 0.05\% v/v (PBST) and the magnetic slide was replaced for $2 \mathrm{~min}$. The beads were washed in PBST in this way once more, the magnetic slide was replaced for $2 \mathrm{~min}$, the supernate was removed and the beads were resuspended in $c .25 \mu \mathrm{l}$ of PBS. Beads were inoculated on to CT-SMAC medium and incubated overnight at $37^{\circ} \mathrm{C}$. Sorbitol non-fermenting colonies were examined as above. Sorbitol non-fermenting colonies that did not agglutinate with the latex test kit for $E$. coli $\mathrm{O} 157$ were identified by a standard series of biochemical tests [1].

\section{Quantification of E. coli 0157}

When possible, quantification of the E. coli 0157 isolates by IMS but not by direct culture was performed by adding $5 \times 1 \mathrm{~g}, 5 \times 0.1 \mathrm{~g}$ and $5 \times 0.01 \mathrm{~g}$ of faeces to $10-\mathrm{ml}$ volumes of $\mathrm{BPW}-\mathrm{VCC}$, vortex mixing, incubating at $37^{\circ} \mathrm{C}$ for $6 \mathrm{~h}$ and performing IMS and examination of sorbitol non-fermenting colonies as above. The most probable number of E. coli $\mathrm{O} 157$ was then estimated by standard methods [13].

\section{Identification}

As described previously [1], isolates that gave a positive latex test result were confirmed as $E$. coli by biochemical tests and confirmed as serogroup 0157 by agglutination to titre with antiserum to $E$. coli $\mathrm{O} 157$ (Laboratory for Microbiological Reagents, Central Public Health Laboratory, 61 Colindale Avenue, London).

\section{Verocytotoxin production}

Toxigenicity was determined by Vero cell culture assay [1]. Toxin type was determined by specific hybridisation with $\mathrm{DNA}$ probes for the $\mathrm{VT}_{1}$ and $\mathrm{VT}_{2}$ genes. DNA specific for the A cistrons of the $\mathrm{VT}_{1}$ and $\mathrm{VT}_{2}$ genes was prepared by the polymerase chain reaction, random-prime labelled with digoxigenin-11-dUTP, and used in colony hybridisation reactions as described previously [2, 14]. Known $\mathrm{VT}_{1}{ }^{+}, \mathrm{VT}_{2}{ }^{+}$and $\mathrm{VT}^{-}$strains were included as controls in each batch of tests.

\section{Plasmid analysis}

Plasmids were extracted by an alkaline detergent method [15] and were separated by submerged gel electrophoresis in Tris-acetate-EDTA buffer with agarose $1 \%$, stained by ethidium bromide and visualised on an ultraviolet transilluminator. A control E. coli $\mathrm{K}-12$ strain (NCTC 50192-39R861) harbouring plasmids of $148,63.4,36$ and $6.9 \mathrm{~kb}$ was included with each batch of tests. For this control strain, the $\log _{10}$ of plasmid size was plotted against distance migrated through the agarose gel and approximate sizes of plasmids from strains of E. coli $\mathrm{O} 157$ were estimated from this graph.

\section{Phage typing}

All E. coli $\mathrm{O} 157$ isolates were phage typed by the Laboratory for Enteric Pathogens, Central Public Health Laboratory. 


\section{Results}

E. coli $\mathrm{O} 157$ was isolated from $10(3.7 \%)$ of 272 patients with acute bloody diarrhoea, three $(0.8 \%)$ of 375 patients with acute non-bloody diarrhoea, eight $(42 \%)$ of 19 repeat samples from these patients and four $(16.7 \%)$ of 24 asymptomatic contacts. Results are shown in detail in Table 1 . Sufficient sample to enable quantification of $E$. coli $\mathrm{O} 157$ was available from only two asymptomatic contacts; in both cases numbers of E. coli $\mathrm{O} 157$ were $<10 \mathrm{cfu} / \mathrm{g}$ of faeces.

The identities of 148 sorbitol non-fermenting organisms which were not $E$. coli 0157 , but which apparently adhered to the magnetic beads, are shown in Table 2. The two most common groups were $E$. coli strains of other serogroups $(32.4 \%)$ and Proteus spp. $(19.6 \%)$.

Characteristics of the 17 primary isolates of $E$. coli O157 are shown in Table 3. Only one strain was nontoxigenic and gave negative results in both cell culture and DNA hybridisation assays; this strain was isolated only by IMS and was from a patient with acute nonbloody diarrhoea. Two strains reacted with the phage set but did not conform to recognised phage types. All strains harboured the $92-\mathrm{kb}$ plasmid which is a common characteristic of VTEC.
Table 2. Sorbitol non-fermenting organisms adhering to E. coli 0157 Dynabeads

\begin{tabular}{lr}
\hline Species & Number (\%) \\
\hline E. coli, not O157 & $48(32.4)$ \\
Hafnia alvei & $17(11.5)$ \\
Morganella morgani & $13(8.8)$ \\
Proteus mirabilis & $11(7.4)$ \\
Proteus vulgaris & $5(3.4)$ \\
Klebsiella ozaenae & $5(3.4)$ \\
Providencia alcalifaciens & $4(2.7)$ \\
Gram-negative organisms & $12(8.1)$ \\
identified to genus level & $33(22.3)$ \\
Gram-negative organisms & \\
not identified to genus level & \\
& \\
Total & 148 \\
\hline
\end{tabular}

\section{Discussion}

Cattle appear to be a major reservoir of $\mathrm{VT}^{+} E$. coli 0157 strains and the organism has been isolated from apparently healthy animals during investigations of sources of human infection in Canada [16], the USA [17-19] and England [1-3]; the enhanced sensitivity of IMS for detecting strains of $E$. coli 0157 in food, milk and bovine faecal samples $[3,11,12]$ has proved useful in epidemiological investigations in the Sheffield area $[3,20]$. However, although primarily a foodborne

Table 1. Comparison of IMS with direct culture on CR-SMAC and CT-SMAC for isolation of E. coli O157 from human faecal samples

\begin{tabular}{|c|c|c|c|c|c|c|c|}
\hline \multirow[b]{2}{*}{ Patient category } & \multirow{2}{*}{$\begin{array}{l}\text { Number of } \\
\text { specimens }\end{array}$} & \multicolumn{3}{|c|}{$\begin{array}{l}\text { Number of cultures } \\
\text { requiring investigation of } \\
\text { SNF colonies from }\end{array}$} & \multicolumn{3}{|c|}{$\begin{array}{c}\text { Number of } E \text {. coli } 0157 \\
\text { isolates obtained by }\end{array}$} \\
\hline & & CR-SMAC & CT-SMAC & IMS & CR-SMAC & CT-SMAC & IMS \\
\hline Bloody diarrhoea & 272 & 9 & 14 & 45 & 8 & 9 & 10 \\
\hline Acute non-bloody diarrhoea & 375 & 10 & 33 & 116 & 1 & 1 & 3 \\
\hline Follow-up samples & 19 & 3 & 4 & 8 & 3 & 4 & 8 \\
\hline Asymptomatic contacts & 24 & 0 & 1 & 4 & 0 & 1 & 4 \\
\hline Total & 690 & 22 & 52 & 173 & 12 & 15 & 25 \\
\hline
\end{tabular}

SNF, sorbitol non-fermenting.

Table 3. Characteristics of 17 strains of $E$. coli 0157 isolated from human faeces by IMS

\begin{tabular}{|c|c|c|c|c|c|}
\hline \multirow[b]{2}{*}{ Phage type } & \multirow{2}{*}{$\begin{array}{l}\text { Vero cell } \\
\text { assay for VT }\end{array}$} & \multicolumn{2}{|c|}{ DNA probes for } & \multirow[b]{2}{*}{ Plasmids (kb) } & \multirow{2}{*}{$\begin{array}{l}\text { Number of } \\
\text { isolates }\end{array}$} \\
\hline & & $\mathrm{VT}_{1}$ & $\mathrm{VT}_{2}$ & & \\
\hline 1 & + & + & + & $92,6.6$ & 1 \\
\hline \multirow[t]{5}{*}{2} & + & - & + & 92 & 7 \\
\hline & + & - & + & $92,7.5,5.7$ & 2 \\
\hline & + & - & + & $92,85,75$ & 1 \\
\hline & + & - & + & 92,60 & 1 \\
\hline & + & - & + & $92,8.3$ & 1 \\
\hline 4 & + & + & + & $92,6.3$ & 1 \\
\hline 32 & - & - & - & 92 & 1 \\
\hline \multirow[t]{2}{*}{ RDNC } & + & - & + & $92,69,2$ & 1 \\
\hline & + & - & + & $92,5,2$ & 1 \\
\hline
\end{tabular}

RDNC, reacted with the phage set but did not conform to a recognised phage type. 
illness, person-to-person transmission has been described, mainly in institutional and family outbreaks [5-7]. Reports vary as to whether person-to-person transmission is facilitated by prolonged excretion of E. coli O157. According to Tarr et al. [21], all those infected with $\mathrm{VT}^{+} E$. coli $\mathrm{O} 157$ had positive faecal cultures up to 2 days after onset of illness, but at $\geqslant 7$ days after onset, only $30 \%$ were positive. In contrast, Belongia et al. [5] found excretion of the organism for up to 62 days and Gransden et al. [22] for up to 28 days. The latter group speculated that prolonged excretion may aid the spread of $E$. coli O157, particularly among children. In the present study, eight of 19 repeat samples from previously positive patients were positive for $E$. coli $\mathrm{O} 157$ but only three and four were positive by direct culture on CR-SMAC and CTSMAC, respectively. These included a 2-year-old child who was shown to be still excreting the organism 3 months after initial onset of symptoms. The role of asymptomatic carriers in the spread of E. coli 0157 infection is not known, but in this study four asymptomatic contacts of cases were found to be positive by IMS - only one of these was detected by direct culture on CT-SMAC but not on CR-SMAC. In two asymptomatic contacts who were positive by IMS only, the numbers of $E$. coli 0157 excreted in the faeces were low ( $<10 \mathrm{cfu} / \mathrm{g})$ and this probably explains their detection only by the IMS technique. However, given the presumed low infective dose of the organism, such carriers may be important in the spread of infection. Therefore, IMS is a useful technique for the monitoring of human infections by $E$. coli $\mathrm{O} 157$ and is more sensitive than direct culture.

All strains isolated by IMS and direct culture were typical of those isolated in the Sheffield area in previous studies. One strain was non-toxigenic, phage type 32 and harboured plasmids of 92 and $2 \mathrm{~kb}$. This strain was isolated from a case of acute non-bloody diarrhoea and although it has been isolated previously from cattle [2], this is the first instance of its isolation from a human source; its significance in relation to the patient's illness is unclear.

The main problem found with the IMS technique was the number of sorbitol non-fermenting micro-organisms other than $E$. coli 0157 that adhered nonspecifically to the magnetic beads (Table 2). At least 10 different types of such organisms were found in the present study with the two most common groups being E. coli strains of other serogroups (32.4\%) and Proteus spp. (19.6\%); these organisms have also been a problem with direct culture techniques [9]. Although this did not detract from an overall $67 \%$ increase in positive samples detected by IMS over direct culture, it did increase the technical time required for the investigations and further work is required to address this problem. IMS is rapid, technically simple and sensitive and should be useful for the monitoring of human infections with $E$. coli $\mathrm{O} 157$.
We thank Dynal (UK) Ltd and Dynal AS (Oslo) for providing coated beads for this study, Dr B. Rowe, Laboratory for Enteric Pathogens, Central Public Health Laboratory for phage typing the E. coli O157 strains, and colleagues at Sheffield and Rotherham Environmental Health Departments for their assistance in obtaining follow-up samples and samples from asymptomatic patients.

\section{References}

1. Chapman PA, Wright DJ, Norman P. Verotoxin-producing Escherichia coli infections in Sheffield: cattle as a possible source. Epidemiol Infect 1989; 102: 439-445.

2. Chapman PA, Siddons CA, Wright DJ, Norman P, Fox J, Crick E. Cattle as a possible source of verocytotoxin-producing Escherichia coli 0157 infections in man. Epidemiol Infect 1993; 111: 439-447.

3. Chapman PA, Wright DJ, Higgins R. Untreated milk as a source of verotoxigenic E. coli O157. Vet Rec 1993; 133: $171-172$.

4. Morgan D, Newman CP, Hutchinson DN, Walker AM, Rowe B, Majid F. Verotoxin producing Escherichia coli 0157 infections associated with the consumption of yoghurt. Epidemiol Infect 1993; 111: 181-187.

5. Belongia EA, Osterholm MT, Soler JT, Ammend DA, Braun JE, MacDonald KL. Transmission of Escherichia coli $\mathrm{O} 157: \mathrm{H} 7$ infection in Minnesota child day-care facilities. $J \mathrm{Am} \mathrm{Med}$ Assoc 1993; 269: 883-888.

6. Karmali MA, Arbus GS, Petric M et al. Hospital-acquired Escherichia coli 0157:H7 associated haemolytic uraemic syndrome in a nurse. Lancet 1988; 1: 526.

7. Ratnam S, March SB, Sprague WD, Severs D, Sullivan RM. Are humans a source of Escherichia coli O157.H7, the agent of hemorrhagic colitis? $N$ Engl J Med 1986; 315: 1612-1613.

8. March SB, Ratnam S. Sorbitol-MacConkey medium for the detection of Escherichia coli $0157: \mathrm{H} 7$ associated with hemorrhagic colitis. J Clin Microbiol 1986; 23: 869-872.

9. Chapman PA, Siddons CA, Zadik PM, Jewes L. An improved selective medium for the isolation of Escherichia coli 0157. $J$ Med Microbiol 1991; 35: 107-110.

10. Zadik PM, Chapman PA, Siddons CA. Use of tellurite for the selection of verocytotoxigenic Escherichia coli O157. J Med Microbiol 1993; 39: 155-158.

11. Wright DJ, Chapman PA, Siddons CA. Immunomagnetic separation as a sensitive method for isolating Escherichia coli O157 from food samples. Epidemiol Infect 1994; 113: 31-39.

12. Chapman PA, Wright DJ, Siddons CA. A comparison of immunomagnetic separation and direct culture for the isolation of verocytotoxin-producing Escherichia coli $\mathrm{O} 157$ from bovine faeces. J Med Microbiol 1994; 40: 424-427.

13. Board RG. A modern introduction to food microbiology. (Basic microbiology vol 8). Oxford, Blackwell Scientific Publications. 1983

14. Chapman PA, Daly CM. Evaluation of non-radioactive trivalent DNA probe (LTh, ST1a, ST1b) for detecting enterotoxigenic Escherichia coli. J Clin Pathol 1993; 46: 309-312.

15. Chapman PA, Jewes L, Siddons CA, Norman P, George SL. Verocytotoxin-producing Escherichia coli infections in Sheffield: 1985-1989. PHLS Microbiol Digest 1990; 7: 163-166.

16. Borczyk AA, Karmali MA, Lior H, Duncan LMC. Bovine resevoir for verotoxin-producing Escherichia coli 0157:H7. Lancet 1987; 1 : 98.

17. Martin ML, Shipman LD, Wells JG et al. Isolation of Escherichia coli O157:H7 from dairy cattle associated with two cases of haemolytic-uraemic syndrome. Lancet 1986; 2: 1043.

18. Ostroff SM, Griffin PM, Tauxe RV et al. A statewide outbreak of Escherichia coli 0157:H7 infections in Washington state. Am J Epidemiol 1990; 132: 239-247.

19. Wells JG, Shipman LD, Greene $\mathrm{KD}$ et al. Isolation of Escherichia coli serotype 0157:H7 and other shiga-like toxin-producing $E$. coli from dairy cattle. J Clin Microbiol 1991; 29: 985-989.

20. Mechie SC, Chapman PA, Siddons CA. A fifteen month field study of Escherichia coli $0157: \mathrm{H} 7$ in a dairy herd. (in press)

21. Tarr PI, Neill MA, Clausen CR, Watkins SL, Christie DL, 
Hickman RO. Escherichia coli O157:H7 and the hemolytic uremic syndrome: importance of early cultures in establishing the etiology. J Infect Dis 1990; 162: 553-556.
22. Gransden WR, Damm MAS, Anderson JD, Carter JE, Lior H. Haemorrhagic cystitis and balanitis associated with verotoxinproducing Escherichia coli O157:H7. Lancet 1985; 2: 150. 